\title{
Hubungan Pengetahuan Kode Etik Kedokteran Tentang Aborsi terhadap Sikap Mahasiswa Kedokteran Terhadap Aborsi
}

\author{
Fandi Muhammad Nugroho', Hari Wujoso², Wahyu Dwi Atmoko² \\ 1. Program Studi Kedokteran Fakultas Kedokteran, Universitas Sebelas Maret \\ 2. Bagian Forensik Fakultas Kedokteran, Universitas Sebelas Maret
}

\begin{abstract}
ABSTRAK
Pendahuluan: Aborsi adalah pengguguran kandungan sebelum usia janin mencapai 22 minggu. Aborsi dibagi menjadi dua, yaitu dialakukan secara buatan atau spontan. Oposisi dari tindakan aborsi berpendapat janin dianggap sebagai manusia, membunuh manusia yang tidak bersalah merupakan tindakan moral yang salah. Secara keseluruhan, 35 aborsi terjadi setiap tahun per 1.000 perempuan berusia 15-44 tahun di seluruh dunia. Dalam menjaga kualitas dan etika tenaga medis, seorang dokter dipandu dalam suatu pedoman norma etik profesi dokter yang disebut Kode Etik Kedokteran Indonesia (KODEKI). Pada penelitian tahun 2016 dikatakan perbedaan pengetahuan etika kedokteran tentang aborsi berpengaruh pada sikap yang diambil dokter untuk melakukan aborsi. Di 2020 ini peneliti mencoba meneliti kembali apakah perbedaan pengetahuan KODEKI tentang aborsi berpengaruh signifikan terhadap sikap yang diambil oleh dokter muda melakukan tindakan aborsi.

Metode: Penelitian ini bersifat observasional analitik dengan pendekatan cross sectional. Subjek dalam penelitian ini adalah mahasiswa Program Studi Kedokteran Fakultas Kedokteran Universitas Sebelas Maret. Uji prasyarat menggunakan uji validitas, uji reliabilitas dan uji normalitas. Bila data terdistribusi normal maka akan digunakan uji korelasi person, sedangkan bila data tidak terdistribusi normal maka digunakan uji spearman.

Hasil: Pada uji normalitas, didapatkan $\mathrm{p}=0,101$ untuk kelompok skor pengetahuan Kode etika kedokteran tentang aborsi dan $\mathrm{p}=0,616$ untuk skor sikap mahasiswa kedokteran terhadap aborsi. Pada uji korelasi Pearson, didapatkan nilai $\mathrm{p}=0,002$ yang menunjukkan bahwa hubungan Pengetahuan Kode Etika Kedokteran Tentang Aborsi dengan Sikap Mahasiswa Kedokteran Terhadap Aborsi bermakna karena $\mathrm{p}<0,05$. Nilai korelasi Pearson sebesar 0,339 menunjukkan bahwa korelasi negatif dengan kekuatan korelasi yang sedang.
\end{abstract}

Kesimpulan: Hubungan pengetahuan kode etika kedokteran tentang aborsi dengan sikap mahasiswa kedokteran terhadap aborsi bermakna secara statistik.

\section{Kata Kunci: Aborsi, Pengetahuan KODEKI, Sikap}

\section{ABSTRACT}

Introduction: Abortion is an abortion before the fetus reaches 22 weeks of age. Abortion is divided into two, namely done artificially or spontaneously. Opposition to the act of abortion argues that the fetus is considered a human being, killing an innocent human being is a moral wrong act. In all, 35 abortions occur annually per 1,000 women aged 15-44 worldwide. In maintaining the quality and ethics of medical personnel, a doctor is guided by a professional ethical norm guideline called the Indonesian Medical Code of Ethics (KODEKI). In a 2016 study, it was stated that differences in medical ethics knowledge about abortion had an effect on the attitudes taken by doctors to perform abortions. In 2020, the researchers tried to re-examine whether the differences in KODEKI's knowledge about abortion had a significant effect on the attitudes taken by young doctors in carrying out abortion.

Methods: This research is an analytic observational study with a cross sectional approach. The subjects in this study were students of the Medical Study Program, Faculty of Medicine, Sebelas Maret University. The prerequisite test used the validity test, reliability test and normality test. If the data is normally distributed, the person correlation test will be used, whereas if the data is not normally distributed, the Spearman test is used.

Results: In the normality test, it was found that $p=0.101$ for the group of knowledge scores on the code of medical ethics about abortion and $p=0.616$ for scores on the attitudes of medical students towards abortion. In the Pearson correlation test, the $p$ value was obtained $=0.002$, which indicates that the relationship between Knowledge of the Code of Medical Ethics on Abortion and the Attitudes of Medical 
Students to Abortion is significant because p <0.05. The Pearson correlation value of 0.339 indicates that the correlation is negative with moderate correlation strength.

Conclusions: The relationship between knowledge of medical ethics code about abortion and attitudes of medical students towards abortion is statistically significant.

Keywords: abortion, KODEKI knowledge, attitude

\section{PENDAHULUAN}

Aborsi adalah pengguguran kandungan sebelum usia janin mencapai 22 minggu. Aborsi dibagi menjadi dua, yaitu dialakukan secara buatan atau spontan. Abortus spontan adalah serangkain proses alamiah untuk menggugurkan hasil konsepsi yang tidak berkembang ataupun tidak normal (keguguran) (Purwaningrum and Fibriana, 2017) ${ }^{1}$.

Sedangkan Aborsi buatan adalah serangkaian proses dan mekanisme untuk mengakhiri kehamilan dengan intervensi tertentu. Aborsi buatan ini dibagi menjadi dua, yaitu aborsi buatan yang legal disebut juga abortus provocatus medicinalis dengan didasarkan keperluan indikasi tindakan medis, Sedangkan, Abortus provocatus criminalis atau aborsi buatan illegal adalah aborsi yang dilakukan tanpa adanya indikasi medik (Hanafiah dan Amir, 2017) ${ }^{2}$.

Aborsi adalah salah satu bahasan yang seringkali menjadi perbincangan yang hangat di tengah masyarakat, di Indonesia maupun di negara lain, dan di berbagai konferensi formal dan informal di seluruh dunia. Aborsi juga merupakan bahasan kontroversional, terutama yang mengkaitkan dengan nilai moral. Banyak masyarakat Indonesia menggangap aborsi adalah hal yang tabu, seperti dikaitkan dengan perzinahan, korban dari pemerkosaan dan korban dari gagalnya alat kontrasepsi. Masyarakat sekarang banyak beralih ke hukum ketika mencoba memutuskan apa solusi terbaik untuk kehamilan yang tidak diinginkan. Masih menjadi subjek yang masih diperdebatkan janin dalam kandungan untuk digugurkan.Bagaimanapun, embrio atau janin dari segala usia dilindungi oleh Hippocratic (Alka B Patil, Pranil Dode, 2014) ${ }^{3}$.

Oposisi dari tindakan aborsi berpendapat janin dianggap sebagai manusia, membunuh manusia yang tidak bersalah merupakan tindakan moral yang salah. Kegiatan aborsi adalah contoh membunuh dan mengakhiri kehidupan manusia. Jadi, terlibat aborsi adalah tindakan moral yang salah. Jika masyarakat menentang tegas dan berkomitmen untuk satu argumen yang mensyaratkan wanita hamil ( disengaja maupun tidak disengaja) harus menanggung proses kehamilan, proses persalinan hingga kelahiran. Gagasan tersebut lebih didasarkan atas "kehidupan janin" daripada alasan ibu harus menanggung penderitaan moral yang terjadi karena kesalahan ibu berupa kehamilan diluar nikah atapun kegagalan kontrasepsi yang dipakainya. Gagasan ini sebagian besar dianut oleh kaum spiritual. Sedangkan yang setuju dengan aborsi berpendapat bahwa hak mengandung itu mutlak hak perempuan atas dirinya sendiri. Jadi yang menentukan janin itu digugurkan atau tidak itu tergantung pada perempuan yang mengandung janin. (Alka B Patil, Pranil Dode, 2014) ${ }^{4}$.

Pengguguran janin merupakan konflik antara dua orang, yaitu hak ibu dan hak janin. Hak ibu atas pilihan untuk memiliki janin atun menggurkannya. Sedangkan pengguran anak bertentangan terhadap Hippocrates yaitu "Saya akan mempertahankan rasa hormat yang terbaik untuk kehidupan manusia, dari saat mulai pembuahan. (Alka B Patil, Pranil Dode, 2014)

Insiden global dan daerah level saat ini. Pada 2010-2014, diperkirakan 55.900 .000 aborsi terjadi setiap tahun, 49.300.000 di daerah berkembang dan 6,6 juta di daerah maju. Sedangkan angka mutlak dipengaruhi oleh ukuran populasi, tingkat tahunan tidak. Secara keseluruhan, 35 aborsi terjadi setiap tahun per 1.000 perempuan berusia 15-44 di seluruh dunia , Regional, 
tertinggi diperkirakan tingkat aborsi adalah di Amerika Latin dan Karibia (44 aborsi per 1.000 wanita, dan tingkat terendah di Amerika Utara dan Oseania (17 dan 19 per 1.000 wanita). Sedangkan di Afrika dan Asia yang sangat dekat dengan rata-rata dunia (34 dan 36 per 1.000). Pada tingkat subregional, tarif cukup homogen di Afrika dan Asia; Namun, mereka bervariasi, di Amerika Latin dan Karibia (dari 33 per 1.000 di Amerika Tengah dan 59 per 1.000 di Karibia), dan di Eropa (dari 16 per 1.000 di Eropa Barat dan 42 per 1000 di Eropa Timur).(Tsuyoshi onda, 2017) . $^{6}$

Sejauh ini, penurunan tertajam di tingkat aborsi terjadi di Eropa Timur, di mana penggunaan kontrasepsi yang efektif meningkat secara drastis; tingkat aborsi juga menurun secara signifikan dalam sub regional berkembang dari Asia Tengah. Kedua subregional terdiri dari negara-negara Rusia karena ketersediaan alat kontrasepsi modern meningkat tajam setelah kemerdekaan-mencontohkan politik bagaimana aborsi turun ketika penggunaan kontrasepsi yang efektif naik (Tsuyoshi onda, 2017) ${ }^{7}$.

Menurut Supas 2015 Angka Kematian Ibu (AKI) Indonesia yang mencapai 305 per 100.000 pada tahun 2015,Total kematian ibu ada sekit 14.640 yang dilaporkan hanya 4.999 sisanya tidak dilaporkan ke pusat. Penyebab langsung kematian ibu tahun 2013 adalah perdarahan obstetrik $27.03 \%$, komplikasi non obstetric $15.7 \%$, hipertensi $33,07 \%$ infeksi pada kehamilan 6.06\%. (Kemenkes RI, 2019) ${ }^{8}$.AKI Jawa Tengah tahun 2014 sebesar 111,16 per100.000 kelahiran hidup dan AKB 10,08/1000 kelahiran hidup (DinkesProv Jateng, 2015) ${ }^{9}$. AKI Kabupaten Semarang tahun 2015 sebanyak 120,34per $100.000 \mathrm{KH}$ dan AKB 11,18 per 1000 kelahiran hidup. (Badan Pusat Statistik, 2015) ${ }^{10}$.

Dikutip dari Vanden Bos dalam American Psychological Association(APA) Dictionary of Psychology aborsi adalah serangkaian peristiwa pengeluaran embrio atau janin secara sengaja taupun tidak sengaja dari rahim ibu sebelum janin mampu hidup di luar rahim , (Setyasari dan Afiatin, 2015,4th. 33) ${ }^{11}$. Masyarakat harus mampu membedakan antara aborsi dengan unsur kesengajaan dan keguran karena terdapat perbedaan individual dalam sikap, mental dan fisik.

Dikutip dari berita CNN Indonesia, klinik tanpa nama di Jakarta ini telah melakukan praketk abortus buatan illegal salama 21 bulan dan tercatat 1.632 pasien yang mendatangi klinik tersebut, dan ada 903 perempuan ibu hamil menggugurkan kandungannya dengan cara abortus provocatus criminalis.

Mutu pelayanan kesehatan dalam rumah sakit sangat ditentukan oleh berbagai faktor salah satunya adalah tenaga medis yang bekerja. Dalam menjaga kualitas dan etika tenaga medis , seorang dokter dipandu dalam suatu pedoman norma etik profesi dokter yang disebut Kode Etik Kedokteran Indonesia (KODEKI). KODEKI merupakan kumpulan peraturan etika profesi yang akan digunakan sebagai tolak ukur perilaku ideal dan penahan godaan penyimpangan profesi. Dalam menjalankan profesinya seorang dokter harus memiliki enam nilai yang terdapat di KODEKI yaitu altruisme, responsibilitas, idealisme profesi, akuntabilitas terhadap pasien, integritas ilmiah dan integritas sosial ( Kodeki,2012 ) ${ }^{12}$. Selain berlandaskan norma-norma etik, etika kedokteran mengutamakan keselamatan pesien dengan prinsip beneficence, non maleficence, autonomy dan justice (Fakultas Kedokteran USU, 2004) ${ }^{13}$.

Pada penelitian tahun 2016 dikatakan perbedaan pengetahuan etika kedokteran tentang aborsi berpengaruh pada sikap yang diambil dokter untuk melakukan aborsi (Sjöström et al., 2016) ${ }^{14}$. Kemudian dilakukan penelitian kembali di 2017 dan menghasilkan adanya hubungan tingkat pengetahuan tentang aborsi terhadap sikap yang diambil remaja, tetapi dengan presentase lebih menurun (Ayu and Kurniawati, 2017) ${ }^{15}$. Di 2020 ini peneliti mencoba meneliti 
kembali apakah perbedaan pengetahuan KODEKI tentang aborsi berpengaruh signifikan terhadap sikap yang diambil oleh dokter muda melakukan tindakan aborsi.

\section{METODE}

Penelitian ini merupakan penelitian observasional analitik dengan pendekatan cross sectional menggunakan kuesioner. Penelitian dilaksanakan di Fakultas Kedokteran Universitas Sebelas Maret. Teknik pengambilan sampel yang digunakan adalah purposive sampling, yaitu setiap mahasiswa kedokteran yang menjalani masa preklinik dan sudah mendapatkan materi KODEKI dan aborsi. Besar sampel menggunakan Rule of Thumb dimana data penelitian yang dianalisis dengan analisis bivariat membutuhkan sampel minimal 30 subjek.

Instrumen penelitian menggunakan kuesioner yang terdiri dari empat bagian, yaitu informed consent, data diri responden, lembar uji pengetahuan mengenai KODEKI, dan kuesioner tentang sikap terhadap aborsi.

\section{HASIL DAN PEMBAHASAN}

\section{Hasil}

Untuk mengetahui hubungan pengetahuan kode etika kedokteran tentang aborsi dengan sikap mahasiswa kedokteran terhadap aborsi digunakan uji korelasi Pearson yang merupakan uji parametric dengan program SPSS 21.0 for Windows. Uji ini bertujuan mengetahui kekuatan korelasi (r) dua kelompok variabel dengan syarat data berskala numeric dan terdistribusi normal. Data dikatakan terdistribusi secara normal bila nilai $\mathrm{p}>0,05$ pada masing masing kelompok. Uji normalitas yang digunakan dalam penelitian ini adalah Kolmogorov-Smirnov. Jika data terdistribusi tidak normal, maka dilakukan transformasi data supaya distribusi menjadi normal. Bila data hasil trasnformasi berdistribusi normal maka dilakukan uji korelasi Pearson, bila hasil transformasi berdistribusi tidak normal maka dilakukan uji korelasi Spearman.

Tabel 1. Uji Normalitas Data dengan Uji Kolmogorov-Smirnov

Data $\quad P \quad$ Keterangan

\begin{tabular}{lll}
\hline Pengetahuan Kode Etika Kedokteran & 0,101 & Distribusi Normal
\end{tabular}

Tentang Aborsi

Sikap Mahasiswa Kedokteran Terhadap $\quad 0,616 \quad$ Distribusi Normal

$\underline{\text { Aborsi }}$

Berdasarkan tabel 1. menunjukkan nilai $\mathrm{p}=0,101$ untuk kelompok skor pengetahuan Kode etika kedokteran tentang aborsi dan $\mathrm{p}=0,616$ untuk skor sikap mahasiswa kedokteran terhadap aborsi. Hasil tersebut membuktikan bahwa data sudah terdistribusi normal.

Tabel 2. Uji Korelasi Pearson

Sikap Mahasiswa Kedokteran Terhadap Aborsi

\begin{tabular}{lcc}
\hline Pengetahuan Kode Etika Kedokteran Tentang & $\mathrm{r}$ & $-0,339$ \\
Aborsi & $\mathrm{p}$ & 0,002 \\
& Arah korelasi & Negatif \\
\hline
\end{tabular}


Dari hasil perhitungan SPSS diperoleh nilai $\mathrm{p}=0,002$ yang menunjukkan bahwa hubungan Pengetahuan Kode Etika Kedokteran Tentang Aborsi dengan Sikap Mahasiswa Kedokteran Terhadap Aborsi bermakna karena $p<0,05$. Nilai korelasi Pearson sebesar 0,339 menunjukkan bahwa korelasi negatif dengan kekuatan korelasi yang sedang.

Hasil analisis penelitian dengan menggunakan uji korelasi Pearson menunjukkan ada hubungan pengetahuan kode etika kedokteran tentang aborsi dengan sikap mahasiswa kedokteran terhadap aborsi memiliki nilai korelasi (r) sebesar $-0,339$ pada taraf signifikansi $\mathrm{p}=$ 0,002 ( $\mathrm{p}<0,05$ ). Hal ini menunjukkan bahwa hubungan antara pengetahuan kode etika kedokteran tentang aborsi dengan sikap mahasiswa kedokteran terhadap aborsi bermakna dan arah korelasi negatif dengan kekuatan korelasi yang sedang.

Dalam hal ini mengapa mahasiswa ada hubungan terhadap sikap negatif terhadap aborsi, di suatu sisi mahasiswa mayoritas nya banyak yang bersifat merantau (ngekos) terdapat kebebasan-kebebasan yang tidak sempat di kontrol oleh orang tua maupun masyarakat setempat, kemudian karena semakin pesat nya alat teknologi terkadang disalah gunakan ke dalam hal-hal perilaku yang tidak baik.

\section{KESIMPULAN}

Berdasarkan hasil analisis data dan pembahasan, dapat disimpulan sebagai berikut :

1. Sebagian besar responden memiliki pengetahuan yang sedang mengenai kode etika kedokteran tentang aborsi.

2. Sebagian besar responden memiliki sikap yang sedang mengenai sikap mahasiswa kedokteran terhadap aborsi.

3. Hubungan pengetahuan kode etika kedokteran tentang aborsi dengan sikap mahasiswa kedokteran terhadap aborsi bermakna $(\mathrm{p}<0,05)$ secara statistik dengan kekuatan korelasi yang sedang dan arah korelasi negatif.

\section{DAFTAR PUSTAKA}

1 Abortion, M. (2014) 'Medical Management of First-Trimester', 123(3), pp. 676-692.

2 Alka B Patil, Pranil Dode, A. A. (2014) 'Medical Ethics in Abortion', Indian Journal of Clinical Practice, 25(6), pp. 544-548. Available at: http://medind.nic.in/iaa/t14/i11/iaat14i11p544.pdf.

3 Amalia, M. (2015) 'FAKTOR RISIKO KEJADIAN ABORTUS ( STUDI DI RUMAH SAKIT ISLAM SULTAN AGUNG SEMARANG ) RISK FACTORS INCIDENT ABORTION ( Studies in Islamic Hospital Sultan Agung Semarang )', 10(1), pp. 23-29.

4 Amer, A. B. (2019) 'Understanding the Ethical Theories in Medical Practice', Open Journal of Nursing, 09(02), pp. 188-193. doi: 10.4236/ojn.2019.92018.

5 Ayu, S. M. and Kurniawati, T. (2017) 'Hubungan Tingkat Pengetahuan Remaja Putri Tentang Aborsi Dengan Sikap Remaja Terhadap Aborsi Di Man 2 Kediri Jawa Timur', Unnes Journal of Public Health, 6(2), p. 97. doi: 10.15294/ujph.v6i2.13736.

6 Benlahcene, A. et al. (2018) 'A Narrative Review of Ethics Theories: Teleological \& Deontological Ethics', Journal of Humanities and Social Science (IOSR-JHSS), 23(1), pp. 
31-32. doi: 10.9790/0837-2307063138.

7 Purwaningrum, E. D. and Fibriana, A. I. (2017) 'Faktor Risiko Kejadian Abortus Spontan', Higeia Jorunal Of Public Health, 1(3), pp. 84-94.

8 Steer, P. J. (2018) 'The language of abortion: time to terminate TOP: AGAINST: "Termination of pregnancy" is less likely than "abortion" to be misunderstood or cause distress', BJOG: An International Journal of Obstetrics and Gynaecology, 125(9), p. 1066. doi: 10.1111/1471-0528.15136.

9 Susanti, R. et al. (1996) 'Payung hukum pelaksaan abortus provokatus pada kehamilan akibat perkosaan', (36).

10 Tsuyoshi onda, S. S. L. R. G. S. . L. K. (2017) 'Uneven Progress and Unequal Access', Abortion Worldwide 2017: Uneven Progress and Unequal Access is available online at, visit https://www.guttmacher.org/report/abortion-worldwide-2017., pp. 1-68.

11 Watson, K. (2018) 'Why we should stop using the term "elective abortion", $A M A$ Journal of Ethics, 20(12), pp. E1175-E1180. doi: 10.1001/amajethics.2018.1175.

12 Hanafiah, J, Amir, A. (2017). Etika Kedokteran \& Hukum Kesehatan. Jakarta: Penerbit Buku Kedokteran EGC. 